\title{
Caracterização da produção científica em Educacão Especial na Bibliotecá Virtual em Saúde (BVS): um estudo bibliométrico
}

\author{
Luciana Pizzani* \\ Suzelei Faria Bello** \\ Maria Cristina Piumbato Innocentini Hayashi***
}

\section{Resumo}

Objetivo: caracterizar, por meio da abordagem bibliométrica, a produção científica em Educação Especial presente nas bases de dados da Biblioteca Virtual em Saúde (BVS). A Biblioeca Virtual em Saúde (BVS) - cujo objetivo é promover a disseminação e uso da informação científica em saúde - é coordenada pelo Centro Especializado da Organização Pan-Americana de Saúde - BIREME. Método: a metodologia da pesquisa envolveu os seguintes passos: revisão de literatura sobre Educação Especial e Bibliometria; coleta de dados no site da Bireme sobre a presença da Educação Especial nas bases de dados; organização, tratamento bibliométrico e análise dos dados coletados utilizando os softwares MS Excel e Vantage Point. Resultados: os indicadores produzidos permitiram sinalizar que o idioma predominante das produções científicas foi o Português; a maioria dos registros foi realizada de forma individual; as temáticas mais abordadas ligam-se à psicologia e à psicologia do desenvolvimento. Conclusão: os indicadores bibliométricos utilizados na pesquisa demarcaram o estado da arte da produção científica em Educação Especial nas diversas bases de dados da Bireme e também demonstraram um campo de interconexões entre Ciências da Saúde e a Educação Especial.

Palavras-chave: Educação Especial; Análise bibliométrica; Avaliação da produção científica.

\section{Characteristics of scientific production in Special Education in Virtual Health Library (VHL): a bibliometric study}

\begin{abstract}
Objective: To characterize, through bibliometric approach, the scientific literature in this Special Education in the databases of the Virtual Health Library (VHL). The VHL is coordinated by BIREME - Specialized Center of the Pan American Health Organization whose objective is to promote the dissemination and use of scientific information in health. Method: The research methodology was performed by observing the following steps: a literature review on education special and bibliometrics, data collection from the site of BIREME about the presence of

\footnotetext{
* Doutoranda Programa de Pós-Graduação em Educação Especial - Universidade Federal de São Carlos (UFSCar). São Carlos, São Paulo, Brasil.

** Doutoranda Programa de Pós-Graduação em Educação Especial - Universidade Federal de São Carlos (UFSCar). São Carlos, São Paulo, Brasil.

*** Professora Doutora do Programa de Pós-Graduação em Educação Especial - Universidade Federal de São Carlos (UFSCar). São Carlos, São Paulo, Brasil.
} 
special education in the databases, organization, processing and bibliometric analysis of data collected using the software MS Excel and Vantage Point. Results: indicators produced allow signal that the predominant language of scientific production was the Portuguese and the majority of records were written individually, the themes addressed were psychology and developmental psychology. Conclusion: These bibliometric indicators characterizing the state of the art of scientific literature in Special Education at the various bases Data Bireme and also showed a field of interconnections between Health Sciences and Special Education

Keywords: Special Education; Bibliometric analysis; Scientific production evaluation.

\section{Introdução}

Desde o surgimento da Educação Especial, verifica-se a existência de um amplo leque de relações científicas que contribuem para o enriquecimento de seu campo teórico e prático na tentativa de complementar conhecimentos. Sua interface com outras diversas áreas de atuação permite dizer que a Educação Especial se faz como componente emergencial da interdisciplinaridade, essa que é, por sua vez, entendida dentro da produção histórica como produto de um processo que foi incorporado na construção do conhecimento, que possibilita a criação de novos paradigmas de aproximações das especialidades sem excluir as generalidades. (JANTSCH, BIANCHETTI, 1997).

Para aquele leitor não muito íntimo de realidades e termos como esse, pode-se exemplificar a interdisciplinaridade entre Educação, Educação Especial e Saúde por intermédio de diversas ações como a vacinação da população, o saneamento básico, a prevenção de acidentes de trabalho, os cuidados médicos e a conscientização da população para o diagnóstico precoce que podem ajudar a prevenir muitas deficiências por meio da divulgação desse tipo de informação a toda sociedade (Pasian, 2008). Essa interdisciplinaridade também pode proporcionar um melhor entrosamento entre os profissionais da saúde e da educação, para que estes, por meio de armazenamento e acesso a informação em bases de dados, desempenhem suas funções com maior eficiência e habilidade. A interdisciplinaridade corresponde aqui a toda atividade vivenciada a partir de diferentes enfoques, abarcando um determinado fenômeno que deve ser estudado por vários e diferentes ramos de conhecimento.

Por essa sua capacidade de relacionamento com outras áreas, a Educação Especial tem assumido, em sua trajetória histórica, um papel de destaque no panorama das políticas governamentais brasileiras voltadas à educação, principalmente a partir da década de 1990, momento em que ocorreu o fortalecimento de um discurso e de propostas que revelam a intenção de garantir educação para todos (PRIETO, 2004). 
Ao direcionar a reflexão para o atendimento de alunos com necessidades educacionais especiais, Mazzota (1990) e Jannuzzi (2004) enfatizaram que a educação especial já subjazia, nas primeiras providências governamentais para a educação dessa população, que ocorreram no final do Segundo Império, mais precisamente em 1854 e 1857, com a criação dos hoje denominados Instituto Benjamim Constant (para cegos) e Instituto Nacional de Educação de Surdos, respectivamente. Em tais momentos, inicia-se o atendimento médico-pedagógico e psicopedagógico aos deficientes, ${ }^{1}$ enfatizando a determinação médica, tanto para o diagnóstico quanto para as práticas escolares, como priorizava os princípios psicológicos.

Entretanto, foi somente em 1961, com a promulgação da Lei de Diretrizes e Bases da Educação Nacional, que se iniciam as ações oficiais incluídas no contexto da política educacional. Antes disso, as iniciativas governamentais restringiam-se às medidas regionalizadas e campanhas nacionais voltadas para o atendimento educacional às pessoas com deficiência auditiva, mental e visual.

Em 1973, criou-se o Centro Nacional de Educação Especial ? Cenesp ?, um órgão central responsável pelo atendimento às pessoas com necessidades especiais. Sempre desenvolvendo seu trabalho sob a responsabilidade do Ministério da Educação e Cultura, o Cenesp, a partir de 1986, passou a ser denominado Secretaria de Educação Especial.

Mesmo com toda denominação pomposa e politicamente correta dos órgãos que gerenciavam e gerenciam a Educação Especial, por muitos anos, ela caracterizou-se pela centralização do poder de decisão e execução, por uma atuação terapêutica e assistencial, que enfatizava o atendimento segregado realizado por instituições especializadas particulares. Soma-se a isso, o aspecto educacional dessa atuação que era totalmente esquecido, ou relegado a uma posição de somenos importância dentro da escala de valores por ela estabelecida.

Essa situação alterou-se gradativamente a partir da promulgação da Constituição Federal em 1988 (BRASIL, 1988). Os documentos oficiais prevêem que aos alunos com necessidades educacionais especiais tenham o atendimento especializado,em turnos contrário: a) em centros capacitados para suprir aquilo que ele carece; b) em unidades escolares das redes de ensino, a fim de que tenham garantidos à educação, preferencialmente, inseridos em turmas de alunos do ensino regular.

No que tange ainda o universo da Educação Especial, outro acontecimento importante que veio contribuir demasiadamente para sua implantação definitiva foi a Declaração de Salamanca, aprovada, em junho de 1994, pelos representantes de 92 governos e 25 organizações internacionais. Com ela, houve uma mudança na concepção da integração social e passou a se discutir a inclusão, estabelecendo-se as orientações necessárias para a ação nacional e internacional, com vista à implementação de uma escola para todos. 
Com base nessa declaração, o Ministério da Educação e do Desporto elaborou, em 1996, a Lei de Diretrizes e Bases da Educação Nacional, enfatizando que:

[...] embora priorizando o atendimento integrado às classes comuns do ensino regular, [...] prevê a manutenção das classes, escolas ou serviços especializados para atender aos alunos que deles necessitam, em complementação ou substituição ao atendimento educacional nas classes comuns. (BRASIL, 2004)

No entanto, para atender a essa clientela, as instituições de ensino público e privado precisam estar preparadas, promover treinamento e capacitação de professores para poder oferecer um ensino de qualidade a todos os alunos. $E$ uma das maneiras pelas quais os professores e demais profissionais têm a oportunidade de aprimorar seus conhecimentos é a leitura dos trabalhos científicos que estão sendo realizados por seus pares nessa sua área de atuação e que mostram a evolução do conhecimento nesse campo.

A produção científica em Educação Especial no Brasil pode ser representada pelo conjunto de produções dos pesquisadores da área que atuam em programas de pós-graduação e que realizam pesquisas divulgadas em livros e periódicos científicos, teses e dissertações, comunicações apresentadas em eventos científicos, constituindo-se uma literatura de referência da área (SILVA, 2004).

A comunicação dos resultados da pesquisa permite que outros profissionais tenham a oportunidade de conhecer, avaliar e questionar problemas que eventualmente possam surgir sobre diversas questões, além de identificar as lacunas, as perspectivas e as tendências nas áreas do conhecimento. Especificamente na área de Educação Especial, as comunicações dos resultados ressaltam temas que revelam reflexões em torno de problemas que envolvem os indivíduos especiais, suas famílias, a escola e a comunidade.

Algumas lacunas são apontadas e abrangem questões relativas às características e potencialidades das pessoas com necessidades especiais; procedimentos e estratégias de ensino efetivas; construção de currículos significativos (incluindo a profissionalização e estratégias para sobrevivência autônoma); tipos de modalidades de serviços apropriados; meios de torná-los acessíveis para despertar o envolvimento da comunidade; organização escolar; políticas públicas; distribuição de recursos, entre outras (UNIVERSIDADE FEDERAL DE SÃO CARLOS - UFSCar, 2010).

Uma vez ciente da existência e da importância de produções científicas enveredadas no estudo da Educação Especial, despertou-se o desejo de caracterizar todo o material disponível presente nas bases de dados da Biblioteca Virtual em Saúde (BVS), por ser uma fonte informacional que tem por finalida- 
de contribuir para a divulgação da produção científica na área da Saúde, promovendo uma melhor qualidade e valorização da vida através da educação, da promoção da saúde e da prevenção de doenças.

Para desenvolver o trabalho pensado, tomou-se como suporte teórico a cientometria (surgida na década de 1960), que é a área que trata da análise de aspectos quantitativos referentes à geração, propagação e utilização de informações científicas, e que tem como finalidade contribuir para o melhor entendimento do mecanismo de pesquisa científica como uma atividade social" (PELLEGRINI FILHO et al., 1997, p.25). E um dos principais fornecedores de informações dessa teoria são os índices bibliométricos, obtidos por meio de uma prática multidisciplinar que começou a ser usada para identificar o comportamento da literatura e sua evolução em contexto e época determinados, que se denomina bibliometria, uma das importantes ferramentas de gestão em Ciência e Tecnologia.

É nesse contexto que surge a cientometria (ou cienciometria), para estudar a evolução, a quantificação do esforço, o comportamento e o impacto social das ciências, abrangendo o sistema de pesquisa como um todo.

\section{Metodologia} guintes etapas:

Para o desenvolvimento dessa pesquisa foram estabelecidas as se-

a) constituição da fundamentação teórica da pesquisa - revisão de literatura sobre Educação Especial e Bibliometria, com o objetivo de fundamentar teoricamente a pesquisa;

b) coleta de dados no site da Bireme sobre a presença da Educação Especial nas bases de dados - seleção dos registros que apresentaram como assunto principal o termo "Educação Especial.";

c) produção dos seguintes indicadores bibliométricos: 1. Quantidade de registros de cada base analisada; 2 . idioma; 3 . tipo de registros; 4. Indicador de colaboração cientifica nas autorias; 5 . Temática dos periódicos;

d) organização e tratamento bibliométrico dos registros coletados utilizando os softwares MS Excel e Vantage Point para elaboração de gráficos e tabelas e apresentação dos dados e análise e interpretação dos resultados encontrados, recuperando-se os conceitos expostos no referencial teórico sobre a produção científica em Educação Especial para fundamentar a análise dos dados obtidos.

Vale ressaltar que os dados coletados e analisados são de domínio público, bases de dados públicas de produção científica, disponibilizadas no endereço eletrônico: www.bireme.br. 


\section{Fonte de dados: o Sistema Bireme e as bases de dados}

Ainterdisciplinaridade pode corresponder a toda atividade vivenciada a partir de diferentes enfoques, abarcando um determinado fenômeno, que deve ser estudado por diversas áreas de conhecimento, o que pode ser entendido como a integração de diversos conteúdos que se convergem para certo objetivo específico (Mazon, Trevisan, 2001); neste caso, verificar a interface entre o campo da Saúde e o campo da Educação Especial.

Para identificar essa interface, foi eleito como fonte de dados o Sistema Bireme composto pelas bases de dados da Biblioteca Virtual em Saúde (BVS).

A Bireme (www.bireme.br) está estabelecida no Brasil desde 1967, com o nome de Biblioteca Regional de Medicina (que originou a sigla BIREME). Desde seu princípio, atende à demanda crescente de literatura científica atualizada pelos sistemas nacionais de saúde e das comunidades de pesquisadores, profissionais e estudantes. Em 1982, passou a chamar-se Centro Latino-Americano e do Caribe de Informação em Ciências da Saúde (conservando, porém, sua sigla, BIREME), para melhor expressar as suas funções orientadas ao fortalecimento $e$ ampliação do fluxo de informação científica e técnica em saúde em toda a região.

Com o surgimento e consolidação da internet como meio predominante de informação e comunicação, o modelo de cooperação técnica evoluiu, a partir de 1998, para a construção e desenvolvimento da Biblioteca Virtual em Saúde (BVS) como espaço comum de convergência do trabalho cooperativo de produtores, intermediários e usuários de informação. A BVS promove o desenvolvimento de uma rede de fontes de informação científica e técnica com acesso universal na internet. Pela primeira vez abre-se a possibilidade real de acesso equitativo à informação em saúde.

A cobertura temática envolve toda a área de Ciências da Saúde, num sentido bem amplo, cobrindo todas as áreas que tenham relação com a saúde humana: Medicina, Saúde Pública, Odontologia, Enfermagem, Veterinária, Engenharia Sanitária, Farmácia e Química, Biologia, Nutrição, Psicologia, Ecologia e Ambiente, etc. Em termos gerais, ela está expressa, em linguagem documentária, no vocabulário controlado que auxilia o documentalista na análise do conteúdo dos documentos a serem ingressados, assim como na sua posterior recuperação e nos Descritores em Ciências da Saúde ? DeCS (esse nome e sigla são adaptações portuguesas e espanholas para nomenclatura inglesa Medical Subject Headings ? $\mathrm{MeSH}$ ?, produzida pela U.S. National Library of Medicine, com uma ampliação para as áreas de Saúde Pública, Homeopatia, Ciência e Saúde e Vigilância Sanitária).

As bases que fizeram parte desta pesquisa foram:

1. Literatura Latino-Americana e do Caribe em Ciências da Saúde (LILACS): compreende a literatura relativa às Ciências da Saúde, publicada nos países da América Latina e do Caribe, a partir de 1982. 
2. Bibliografia Brasileira de Odontologia (BBO): base de dados de literatura nacional na área de saúde oral, disponibilizada a partir de 1986, de responsabilidade do Serviço de Documentação Odontológica da Faculdade de Odontologia da USP.

3. Base de Dados em Enfermagem (BDENF): base criada em 1988, numa tentativa de facilitar o acesso e a difusão das publicações da área, normalmente ausente das bibliografias nacionais e internacionais. Foi desenvolvida pela Biblioteca J. Baeta Vianna, do Campus da Saúde/UFMG.

4. Literatura do Caribe em Ciências da Saúde (MedCarib): base que reúne a literatura em Ciências da Saúde gerada principalmente nos países do Caribe de língua inglesa. É produzida pela Rede Caribenha e coordenada pelo Centro Coordenador da Rede MedCarib The Medical Library, University of the West Indies - Jamaica.

5. Acervo da Biblioteca da Organização Pan-americana da Saúde (PAHO): contém referências bibliográficas e resumos do acervo da Biblioteca da sede da Organização Pan-americana da Saúde em Washington, D.C. (USA), abrange a documentação sobre temas em Saúde indexada pela Biblioteca.

6. Sistema de Informação da Biblioteca da OMS (WHOLIS): é uma base de dados bibliográfica que contém publicações da sede da Organização Mundial da Saúde (OMS) e das Representações Regionais, artigos de periódicos, documentos técnicos e políticos, e publicações da OMS em colaboração com outros editores e organizações internacionais.

As demais bases que compõem a BVS não foram selecionadas para a pesquisa porque serão estudadas em outra oportunidade.

\section{Levantamento da produção científica nas bases de dados}

Primeiramente verificou-se a existência do termo "educação especial" no vocabulário controlado DeCS, caracterizado como "educação do indivíduo que notadamente diverge intelectual, física, social ou emocionalmente daqueles considerados normais e assim requer instrução especial".

Após a confirmação da existência do termo, acessamos a homepage da Bireme e fizemos a busca em cada base separadamente, selecionando os registros que apresentaram como assunto principal o termo Educação Especial. O período selecionado para a coleta de dados foi de 1981 a 2007 e a coleta de dados foi realizada no dia 14 de fevereiro de 2008. 


\section{Resultados e análises dos dados}

Utilizando a expressão de busca "educação especial" no campo descritor de assunto, foram recuperados 183 registros, distribuídos da seguinte maneira:

Tabela 1 - Número de registros obtidos por base de dados

\begin{tabular}{|c|c|c|}
\hline Bases consultadas & Frequência absoluta & Frequência relativa (\%) \\
\hline LILACS & 167 & 91,25 \\
\hline MEDCARIB & 8 & 4,38 \\
\hline WHOLIS & 3 & 1,63 \\
\hline BBO & 2 & 1,1 \\
\hline BDENF & 2 & 1,1 \\
\hline PAHO & 1 & 0,54 \\
\hline TOTAL & 183 & 100 \\
\hline
\end{tabular}

Fonte: www.bireme.br - Data da Coleta: 14/02/2008

A contagem das publicações se torna um indicador bibliométrico importante, pois pode colaborar com a política de revisão científica destinada a medir e avaliar as contribuições à ciência, tornando-se um instrumento de análise para difundir os achados científicos (SAES, 2000).

\section{Indicadores de idioma}

Nas bases BBO, BDENF e Lilacs os idiomas predominantes foram o português e espanhol, pois são bases que foram criadas com o objetivo de proporcionar maior visibilidade à produção científica em ciências da saúde produzida nos países da América Latina e do Caribe, onde esses idiomas são predominantes.

Nas bases MedCarib e Wholis o idioma que prevaleceu foi o inglês, confirmando o objetivo dessas bases que foram criadas para proporcionar representatividade à produção científica internacional produzida na área médica e biomédica nos Estados Unidos e em mais de 70 países

Na base Lilacs dois registros possuem o idioma inglês e português, como demonstra a Tabela 2. 
Tabela 2 - Indicadores de idioma

\begin{tabular}{|c|c|c|c|}
\hline Bases & Idioma & $\begin{array}{c}\text { Frequência } \\
\text { absoluta }\end{array}$ & Frequência relativa (\%) \\
\hline BBO & Português & 2 & 1,08 \\
\hline BDENF & Português & 2 & 1,08 \\
\hline MEDCARIB & Inglês & 8 & 4,33 \\
\hline PAHO & Espanhol & 1 & 0,54 \\
\hline WHOLIS & Inglês & 3 & 1,62 \\
\hline LILACS & Português & 119 & 64,32 \\
\hline & Espanhol & 48 & 25,95 \\
\hline & Inglês & 2 & 1,08 \\
\hline TOTAL & & 185 & 100 \\
\hline
\end{tabular}

Fonte: www.bireme.br

Data da coleta: 14/02/2008

No que se refere à predominância do idioma inglês, outro fator relevante a ser observado é o fato de ele ser a língua universal da Ciência, permitindo assim que pesquisadores de todo o mundo compreendam o material que está sendo publicado nas revistas científicas (QUELUS, 2002).

\section{Indicadores da tipologia dos registros}

Com relação à tipologia dos registros, constatou-se que as bases em estudo são formadas por diversos tipos de documentos, englobando os artigos de periódicos, teses, livros, capítulos de livros, anais de congressos e conferências e manuais. A definição de cada tipo de publicação encontra-se no site da Bireme e aqui se encontra resumidamente.

- Artigo original (artigo clássico) pode ser definido como a apresentação atual de um artigo impresso previamente e que estabelece um marco na história da medicina ou ciência. É geralmente acompanhado de comentários introdutórios, salientando sua republicação, geralmente no aniversário de sua publicação original ou no aniversário de nascimento ou morte de seu autor.

- Relatos de casos são as apresentações clínicas que podem ser seguidas pelos estudos avaliativos que conduzem eventualmente a um diagnóstico. 
- Revisão de um artigo ou livro é entendido como um exame do material já publicado sobre um determinado assunto. O material textual examinado pode ser amplo e pode abarcar, especificamente em medicina, material clínico assim como pesquisa experimental ou relatos de caso. Revisões do estado-daarte tendem a tratar de assuntos mais atuais.

- Livros e os capítulos de livros são destinados para uso no estudo de assuntos específicos, contendo apresentação sistemática dos princípios e conhecimentos essenciais dos assuntos.

- Dissertações acadêmicas são representadas pelos trabalhos que consistem em apresentações formais usualmente para cumprir os requisitos para um grau acadêmico.

- Trabalhos de congresso são trabalhos apresentados em congressos científicos e publicados em periódicos.

- Manuais são trabalhos de referência concisos nos quais fatos e informação pertinentes a certo assunto ou campo são colocados para pronta referência e consulta ao invés de para leitura e estudo contínuo.

A tipologia dos 185 registros encontrados nas bases de dados da BVS foram distribuídos conforme a Figura 1.

Figura 1 - Indicadores da tipologia dos registros

Indicadores da Tipologia dos Registros

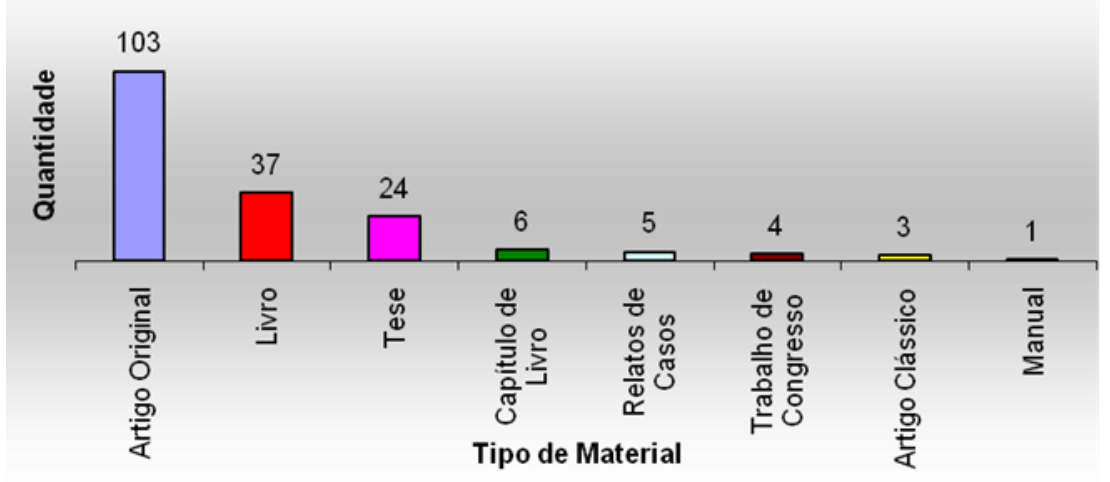

Figura 1 - Indicadores da tipologia dos registros 
Verificou-se que o artigo científico foi o tipo de publicação predominante com 93 registros, seguido do livro (37), Tese (24), Capítulo de livro (6), Relatos de casos (5), Trabalho de congresso (4), Artigo clássico (3) e Manual (1).

O fato de os artigos representarem a grande maioria dos trabalhos encontrados deve-se à questão de os periódicos buscarem cumprir os critérios de seleção para indexação em bases de dados referente ao caráter científico dos trabalhos como é o caso da base de dados Lilacs. Dentro do item "conteúdo" há uma pontuação quanto à natureza dos artigos, e a pontuação maior é para o item "maioria de artigos originais" (SOUZA; PAULA, 2002).

A presença do livro deve-se o ao fato de que os pesquisadores atuantes na área de Educação priorizam a publicação em livros e capítulos de livros, sendo esses considerados os principais canais de comunicação existentes entre os pesquisadores e um público leitor.

No que concerne à dissertação e teses, e, conforme alertam Miranda e Pereira (1996), o conhecimento que é produzido no Brasil sob a forma dessas duas modalidalidades de documentação acadêmica ainda não é publicado com a frequência necessária à incorporação de novas contribuições para o avanço de alguma área. Sendo assim, os organizadores da BVS tiveram o cuidado de contemplar as bases de dados com os vários tipos de publicações produzidas pelos pesquisadores, contribuindo para a visibilidade e acesso da produção científica produzida na América Latina e Caribe.

Em menor escala, mas não menos importantes, encontraram-se os trabalhos de eventos que são resultados das participações dos pesquisadores em congressos. Como as bases de dados priorizam a indexação de artigos originais, já mencionado anteriormente, os trabalhos de eventos são indexados em menor escala. Convém destacar, conforme Silva (2004), que a participação em eventos científicos também abre portas e incentivos para novas publicações.

\section{Indicadores de colaboração científica nas autorias}

O conceito de colaboração científica nas autorias foi elaborado primeiramente por Smith, em 1958, seguido por Price, em 1963. Smith preocupou-se em observar o crescimento da incidência de artigos em coautoria, e sugeriu que esses pudessem ser usados como uma medida aproximada da colaboração entre grupos de pesquisa. Price, em 1963, ao usar empiricamente as observações de Smith, encontrou evidências do aumento de autorias múltiplas na Ciência. De acordo com sua visão, a colaboração científica acontecia no âmbito dos chamados "colégios invisíveis", que se constituíam em comunidades informais de pesquisadores que se comunicavam, trocavam informações e experiências e também publicavam formalmente seus resultados no campo do conhecimento científico. (SILVA, 2008). 
Para Velho (2001, p. 59),

[...] as comunidades informais de pesquisadores encontram-se em congressos, conferências, reuniões sobre suas especialidades, visitam-se por meio de intercâmbios institucionais ou realizam trabalhos em colaboração. Este tipo de organização transcende os limites do departamento, da instituição, de um país, e abrange cientistas de todos os lugares do mundo onde tiver atividade científica relevante na área, ou na especialidade em questão.

Com o objetivo de identificar a ocorrência dessa rede de colaboração científica nos registros selecionados, foi elaborado, junto a todo material destinado à pequisa, um levantamento concernente a essa questão, cujo resultado é apresentado na Figura 2.

Figura 2 - Indicadores de colaboração científica nas autorias

\section{Indicadores de colaboração científica nas autorias}

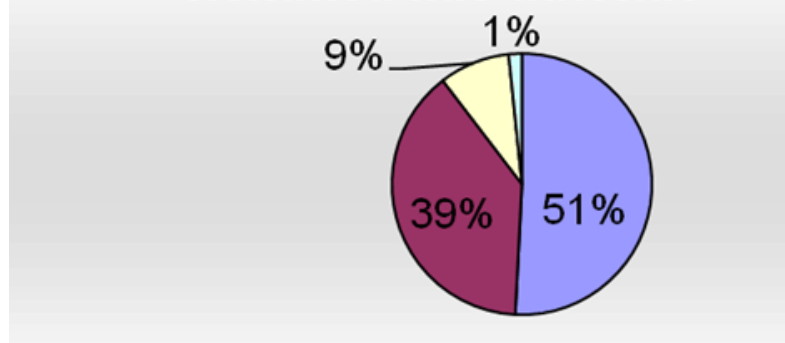

口Autoria Individual $\quad$ Autoria Coletiva

Figura 2 - Indicadores de colaboração científica nas autorias

Constata-se que 50\% (93) dos registros possuem autoria individual, $39 \%$ (71) possuem autoria coletiva, 9\% (16) possuem autoria institucional e apenas 2\% (3) dos registros não possuíam o campo autor preenchido.

Sendo assim, destaca-se que na BVS, a maioria dos registros que tratam sobre a temática Educação Especial é escrita de forma individual. Isso se deve à presença de diversos tipos de materiais indexados como livros, capítulos de livros e teses que, por sua natureza, são escritos por um único autor, e 
também ao fato de que a autoria múltipla é muito mais alta nas Ciências Exatas e Naturais do que nas Humanas e Sociais.

Segundo Velho (1997), isso ocorre porque, nas Ciências Humanas e Sociais, é preciso muito esforço para atingir concordância em várias decisões, tornando o processo muito difícil e o conflito iminente. A colaboração deixa de ser uma vantagem para o cientista. O produto final nessas áreas freqüentemente tem um caráter ensaístico e individual, dificultando a concordância de conteúdo e estilos. Isso significa que a colaboração não só é mais difícil em áreas nas quais os cientistas partilham o mesmo paradigma, mas também naquelas mais codificadas e menos literárias.

\section{Indicadores das temáticas dos periódicos}

Para verificação das temáticas dos periódicos, no site da Bireme (www.bireme.br), clica-se em catálogo de revistas científicas e no campo pesquisa digita-se o título do periódico.

Nos achados dessa pesquisa, verificou-se que dos 183 registros, 111 foram artigos de periódicos publicados em 58 títulos. Na Tabela 3 apresentamos as temáticas dos periódicos. 
Tabela 3 - Identificação das temáticas dos periódicos

\begin{tabular}{|c|c|c|}
\hline Temáticas dos Periódicos & $\begin{array}{l}\text { Frequência } \\
\text { Absoluta }\end{array}$ & $\begin{array}{l}\text { Frequência } \\
\text { relativa }\end{array}$ \\
\hline $\begin{array}{l}\text { Psicologia, Psicologia do } \\
\text { desenvolvimento }\end{array}$ & 42 & 37,83 \\
\hline Distúrbios da comunicação & 13 & 11,71 \\
\hline Pediatria & 13 & 11,71 \\
\hline Medicina & 12 & 10,81 \\
\hline $\begin{array}{l}\text { Psiquiatria, transtornos mentais, } \\
\text { neurologia }\end{array}$ & 7 & 6,3 \\
\hline Hospitais & 5 & 4,5 \\
\hline Enfermagem & 4 & 3,61 \\
\hline Odontologia & 3 & 2,71 \\
\hline Medicina esportiva & 3 & 2,71 \\
\hline $\begin{array}{c}9 \text { assuntos com } 1 \text { frequênca } \\
\text { (Oftalmologia, Saúde pública, } \\
\text { Fisioterapia, Epidemiologia/Doenças } \\
\text { infecciosas, Reabilitação, } \\
\text { Otorrinolaringologia, Serviços de } \\
\text { Saúde, Medicina Ocupacional, } \\
\text { Biologia) }\end{array}$ & 9 & 8,11 \\
\hline Total & 111 & 100 \\
\hline
\end{tabular}

Fonte: www.bireme.br - Data da Coleta: 14/02/2008

Observa-se que as temáticas dos periódicos mais abordados foram "Psicologia" e "Psicologia do desenvolvimento" com freqüência de 37,83\% (42), seguida pela "Pediatria" e os "Distúrbios da comunicação" com 11,71\% (13), "Medicina" 10,81\% (12), "Psiquiatria", "Transtornos mentais" e "neurologia" com 6,30\% (7), "Hospitais" 4,50\% (5), "Enfermagem" 3,61\% (4), "Odontologia" 2,71\% (3), "Medicina esportiva" 2,71\% (3).

Facci, Tuleski e Barroso (2006) argumentam que na educação de pessoas com necessidades educacionais especiais, deve-se considerar que as necessidades especiais e as possibilidades compensatórias capazes de levar à superação das limitações biológicas existem concomitantemente, sendo que a Psicologia pode oferecer os fundamentos para o desenvolvimento de estratégias e procedimentos educativos mediadores para os indivíduos com deficiências ou necessidades singulares. 
Para Glat (2008), a atuação do psicólogo se faz também por meio do estabelecimento de uma relação saudável em que exista a aceitação do indivíduo e valorização de seus pontos positivos, e, ao mesmo tempo, o estabelecimento de limites de conscientização de suas áreas de dificuldades. Percebese a forte ligação existente entre a área da Saúde e da Educação Especial, pois as fontes de pesquisa foram as bases de dados da BVS.

Jannuzzi em 2004, explicou a ligação entre a Educação Especial e as diversas áreas do conhecimento, inclusive a área da Saúde. Segunda a autora, existem três vertentes que ilustram o caminho para a educação das pessoas necessidades especiais: a vertente pedagógica, a médico-pedagógica e a psicopedagógica.

A vertente pedagógica pode ser entendida como as tentativas práticas para vencer os desafios. É a observação e o esforço cotidiano de pessoas empenhadas em ajudar por meio de conhecimentos obtidos nas diversas ciências.

Na vertente médico-pedagógica, os médicos procuravam, desde o século XVI, respostas para os casos mais graves, resistentes ao tratamento terapêutico recorrendo à anatomia e à observação. Relacionavam a deficiência mental a problemas básicos de saúde, doenças degenerativas, sífilis, tuberculose, doenças venéreas. Perceberam a importância da Pedagogia, criando instituições escolares ligadas a hospitais psiquiátricos, congregando crianças que estavam segregadas juntamente com adultos loucos. Essa visão começa a mudar a partir de 1909, com Clemente Quaglio, que defende a ideia de que a escola deveria preparar a criança para a vida moderna.

Assim podemos perceber que a educação de pessoas com necessidades especiais passa de ações assistencialistas à identificação precoce dos chamados indivíduos de risco.

É importante considerar, conforme esclarece Martinez (2007), que a ação preventiva pode ocorrer em três níveis: prevenção primária, secundária e terciária. A intervenção primária visa à redução da incidência de determinadas condições de excepcionalidade na população por meio da identificação, remoção ou redução de fatores de risco que produzem tais condições. São consideradas ações primárias: programas educativos e desenvolvimento e de controle do meio ambiente (antipoluição), instalação de centros de diagnóstico precoce, serviços para crianças adotivas e lares substitutos, programas educacionais para menores (creches e pré-escolas), entre outras.

A prevenção secundária é aquela que tem lugar após se constatar que as condições de excepcionalidade já se instalaram. Exemplos de ações preventivas secundárias são as desenvolvidas pelos centros de diagnóstico e tratamento das crianças de alto risco e risco comprovado, programas de educação da comunidade e a formação de recursos humanos para atuar com população em creches e pré-escolares. (MARTINEZ, 2007). 
Na prevenção terciária, procura-se reduzir as sequelas ou efeitos associados da excepcionalidade por meio de ações que visem a minimizar a necessidade de institucionalização, maximizar o potencial de vida independente, reduzir à ocorrência de comportamentos autolesivos estereotipados e de posturas corporais inadequadas, auxiliar a família a elaborar situações de conflito e de estresse emocional. (MARTINEZ, 2007)

Pasian (2008) também enfatiza a necessidade de se investir primeiro nos cuidados que podem evitar a deficiência, alertando para os cuidados, precauções e, principalmente, informação à população. A autora cita inúmeros fatores que facilitam a prevenção da deficiência, entre eles:

* saneamento básico e educação sanitária, evitando-se, desse modo, diversas doenças que podem causar danos irreversíveis ou a morte;

* proteção contra acidentes, pois muitos podem ser evitados com orientações e materiais adequados, como o uso de protetores auriculares pelos funcionários das indústrias onde o nível de ruído é elevado;

* evitar doenças contagiosas por meio da vacinação, orientação e divulgação;

* tratar da cura das doenças o mais cedo possível para evitar consequências irreversíveis;

* exames realizados no nascimento dos bebês, como o teste do pezinho ou testes que podem diagnosticar uma futura surdez ou cegueira;

* orientação aos pais sobre o pré-natal e os cuidados básicos que devem ter com o bebê pode evitar uma futura deficiência.

\section{Considerações finais}

O aumento da visibilidade da produção do conhecimento culminou com a expansão dos meios tecnológicos, permitindo disponibilizar e acessar as mais variadas informações em tempo e espaço diferenciados

É nesse contexto de evolução tecnológica e preocupações em responder às necessidades de informação que surgiu a Bireme em 1967, sediada na Universidade Federal do Estado de São Paulo (UNIFESP) com a finalidade de atender à demanda crescente de literatura científica atualizada que os sistemas nacionais de saúde e das comunidades de pesquisadores, profissionais e estudantes impetraram.

A cobertura temática das bases de dados envolve todas as áreas que tenham relação com a saúde humana entre elas a Educação Especial, que, por meio da bibliometria, foi possível estabelecer indicadores que representaram a temática da Educação Especial nas bases LILACS, BBO, BDENF, MEDCARIBE, PAHO e WHOLIS. 
Neste contexto, observou-se que o idioma predominante nos artigos da BVS foi o inglês; a maioria dos registros foi escrita em colaboração com temáticas voltadas para a Psicologia e Psicologia do desenvolvimento envolvendo temas como retardo mental, educação do deficiente mental, pessoas com deficiência auditiva, reabilitação, ensino e transtornos da audição.

De forma salutar, esses indicadores podem colaborar com os pesquisadores da área da Educação Especial na interface com a Saúde em vários aspectos. O primeiro deles é a divulgação da existência da BVS como uma importante fonte de informação para a coleta de dados e disseminação das pesquisas realizadas dentro das universidades. Também revela não só os grandes avanços recentes na área, mas também aponta as lacunas no conhecimento relativo a problemas que envolvem os indivíduos especiais, suas famílias, a escola e a comunidade, cuja solução depende da investigação científica e de intervenções que estejam embasadas cientificamente.

O desenvolvimento do tema tratado neste artigo encontra-se delimitado na escolha de determinadas bases disponíveis no sistema Bireme. Aquelas que não foram contempladas na presente análise, por razões diversas e adversas ao desejo de o fazer, serão analisadas oportunamente e, assim, será possível traçar com a ajuda de novos indicadores bibliométricos, a cartografia da produção científica em Educação Especial em bases de dados nacionais e internacionais.

O próprio campo de conhecimento da Educação Especial clama por novos estudos nessa direção, visto que a educação de pessoas com necessidades especiais exige de todos os envolvidos um olhar reflexivo e ativo para demarcar novos caminhos que proporcionem a essas pessoas uma melhor qualidade de vida.

\section{Referências}

ABREU, I.M.C. et al. Significado do controle da produção científica na universidade: o caso da UFSM. 15p. Disponível em: <http://www.anpad.org.br>. Acesso em: 29 out. 2003.

BIREME. Organização Pan-americana de Saúde. Organização Mundial de Saúde. Biblioteca Virtual em Saúde e o controle bibliográfico da produção científica da América Latina e Caribe: o sistema e bases de dados LILACS. São Paulo, 2006. 6p. Disponível em: <http://bvsmodelo.bvsalud.org>. Acesso em: 2 abr. 2008.

BRASIL. Constituição da República Federativa do Brasil. Brasília: Senado Federal, 1988.

BRASIL. Lei n. 9.394. Lei de Diretrizes e Bases da Educação Nacional LDB. Disponível em: <http://www.mec.gov.br/legis/pdf/lei9394.pdf>. Acesso em: out. 2004. 
JANNUZZI, G.M. A educação do deficiente no Brasil: dos primórdios ao início do século XXI. Campinas: Autores Associados, 2004. 243p. (Coleção Educação contemporânea).

JANTSCH, A.P.; BIANCHETTI, L. Imanência, história e interdisciplinaridade. In: . (Orgs.). Interdisciplinaridade: para além da filosofia do sujeito. Petrópolis: Vozes, 1997.

MAZZON, L.; TREVISAN, M.A. Fecundando o processo da interdisciplinaridade na iniciação científica. Revista Latino-Americana de Enfermagem, v. 9, n. 4, p. 83-87, 2001.

MAZZOTA, M. J. S. História da Educação Especial no Brasil. In: DIAS, T. R. S. et al. (Orgs.). Temas em Educação Especial. São Carlos: UFSCar, PPGEES, 1990. p. 106-107.

MIRANDA, D. B.; PEREIRA, M. N. F. O periódico científico como veículo de comunicação: uma revisão de literatura. Ciência da Informação, v. 25, n. 3, p. 375-382, 1996.

MIRANDA, L. P.; RESEGUE, R.; FIGUEIRA, A. C. M. A criança e o adolescente com problemas do desenvolvimento no ambulatório de pediatria. Jornal de Pediatria, v. 79, supl.1, p. 33-44, 2003.

PASIAN, M. S. Educação Especial: a prevenção das deficiências e a busca de melhoras para amenizar a deficiência adquirida. Psicopedagogia Online, p. 1-4, 2008. Disponível em: <http://psicopedagogia.com.br>. Acesso em: 25 jun. 2010.

PELLEGRINI FILHO, A.; GOLDBAUM, M.; SILVI, J. Producción de artículos científicos sobre salud em seis países da América Latina, 1973 a 1992. Revista Panamericana de Salud Publica, v. 1, n. 1, p. 23-34, 1997.

PRIETO, R. G. Políticas públicas de inclusão: compromissos do poder público, da escola e dos professores. p.1-11. Disponível em: <http:// www.educacaoonline.pro.br>. Acesso em: 03 set. 2004.

QUELUZ, T. H. A. T. Admissão do Jornal de Pneumologia na Scielo Brasil: uma vitória com novos desafios. Jornal de Pneumologia, v. 28, n. 1, p. ix-x, 2002.

SILVA, M. A. Análise bibliométrica da produção científica docente do Programa de Pós-Graduação em Educação Especial da UFSCar: 1998-2003. 2004. 168f. Dissertação (Mestrado) - Programa de Pós-graduação em Educação Especial, Universidade Federal de São Carlos, São Carlos.

SILVA, R. C. Indicadores bibliométricos da produção científica em Educação Especial: estudo da Revista Educação Especial (2000-2006). 2008. $118 f$. Dissertação (Mestrado) - Programa de Pós-Graduação em Educação Especial, Universidade Federal de São Carlos, São Carlos. 
SOUZA, E. P.; PAULA, M. C. Qualis: a base de qualificação dos periódicos científicos utilizados na avaliação CAPES. InfoCapes Boletim Informativo, v. 10, n. 2, p. 1-149, 2002.

UNIVERSIDADE FEDERAL DE SÃO CARLOS - UFSCar. Programa de PósGraduação em Educação Especial. Proposta. São Carlos, 2010. Disponível em: $<$ http://www2.ufscar.br/interface_frames/index.php?link=http:// www.cech.ufscar.br/ppgees.htm>. Acesso em: 10 maio 2010.

VELHO, L. Notas sobre a pós-graduação em Ciências Sociais e Humanidades: por que e em que diferem das ciências naturais? Brasília: UNESCO, 1997.

VELHO, L. Redes regionais de cooperação em C\&T e o Mercosul. Parcerias Estratégicas, n.10, p.58-74, 2001.

Notas

1 São múltiplas as designações para as pessoas com deficiências e o uso do termo está relacionado ao contexto histórico-social recebendo influências, inclusive, das legislações e de documentos oficiais. Neste artigo, os autores mencionados no texto adotaram diferentes termos para designar essas pessoas: "indivíduos ou pessoas com necessidades especiais", "portador de necessidades especiais" e "alunos com necessidades educativas especiais".

\section{Correspondência}

Luciana Pizzani - Universidade Federal de São Carlos, Programa de Pós-graduação em Educação Especial, Rudovia Washington Luis, Km 235, CEP 13560-000, São Carlos, São Paulo, Brasil.

E-mail: lupizzani@hotmail.com

Recebido em abril de 2010

Aprovado em outubro de 2010 